\title{
Methods of Cost Estimates for the Operation on Radio Engineering Means Taking Into Account the Discount Factor
}

\author{
Andrey A. Tsyganov and Anna V. Boicova* \\ Military Academy of Aero-Space Defence \\ named after the Marshal of Soviet Union G.K. Zhukov \\ 50 Zhigareva Str., Tver, 170022, Russia
}

Received 14.12.2017, received in revised form 02.01.2018, accepted 24.03.2018

Currently, issues is devoted to the analysis and the cost estimate stages of operation of the radio engineering means is given insufficient attention. It should be noted the relevance of the assessment of these cost, the choice of a rational variant of the equipment of radio engineering means. In the article for this phase of the life cycle of electronic means of operation stages of the proposed method of estimating cost for each of ethans operation and for the stages of operation of radio engineering means in general, account the discount factor.

Keywords: exploitation, life cycle, radio engineering means, cost, repair, operating time, discount factor.

Citation: Tsyganov A.A., Boicova A.V. Methods of cost estimates for the operation on radio engineering means taking into account the discount factor, J. Sib. Fed. Univ. Eng. technol., 2018, 11(3), 347-357. DOI: 10.17516/1999-494X-0047.

(c) Siberian Federal University. All rights reserved

* Corresponding author E-mail address: mto04101983@yandex.ru,glamfeed@mail.ru 


\title{
Методика оценки затрат
}

\section{на эксплуатацию радиотехнического средства с учетом коэффициента дисконтирования}

\author{
А.А. Цыганов, А.В. Бойкова \\ Военная академия воздушно-космической обороны \\ им. Маршала Советского Союза Г.К. Жукова \\ Россия, 170022, Тверь, ул. Жигарева, 50
}

В настоящее время вопросам, посвященным анализу и оценке затрат стадии эксплуатации радиотехнического средства, уделено недостаточное внимание. При этом следует отметить актуальность оценки этих затрат при выборе рационального варианта оснащения радиотехническими средствами группировки радиотехнических войск. В статье рассматриваются затраты на такую стадию жизненного иикла радиотехнического средства, как эксплуатащия, проведен анализ этапов эксплуатащии и предложена методика оценки затрат для каждого этапа эксплуатации и для стадии эксплуатащия радиотехнического средства в иелом, с учетом коэффициента дисконтирования.

Ключевые слова: эксплуатачия, жизненный ичил, радиотехническое средство, затраты, ремонт, наработка, коэффиииент дисконтирования.

Неотъемлемым элементом планирования развития и разработки вооружения военной и специальной техники является проведение тактико-технико-экономического анализа, который заключается в комплексном оценивании боевых, технических и эксплуатационных свойств радиотехнического средства (РТС), а также затрат, необходимых для ее создания и обеспечения функционирования. Назначением трех взаимосвязанных составных частей тактико-техникоэкономического анализа ВВСТ служит выполнение следующих процедур: тактический анализ, технический анализ и экономический анализ [1].

Несмотря на то что стоимость жизненного цикла образца и его структура зависят от типа военной техники, в целом она определяется совокупностью четырех основных стадий и соответствующих им вложений на разработку и исследование, военное строительство, закупку оборудования, эксплуатацию и обслуживание, утилизацию. В табл. 1 представлено процентное распределение расходов по стадиям жизненного цикла, разработанное американским Институтом исследования системы обороны.

Как показывает практика, наибольший удельный вес в общей структуре затрат приходится на стоимость эксплуатации и обслуживания. В соответствии со сложившейся практикой в большинстве работ превалирует пропорция 70:30, принятая в качестве истины, не требующей доказательства.

Процедуры тактического и технического анализа достаточно подробно изложены в [2], поэтому в рамках данной статьи будет рассмотрена процедура экономического анализа с точки зрения оценки затрат на этапе эксплуатации образца РТС. 
Таблица 1. Процентное распределение расходов на стадии жизненного цикла, в зависимости от типа военной системы

Table 1. The percentage distribution of costs at the stage of the life cycle, depending on the type of military system

\begin{tabular}{|l|c|c|c|}
\hline \multicolumn{1}{|c|}{ Тип системы } & \multicolumn{1}{|}{$\begin{array}{c}\text { Разработки } \\
\text { и исследование, \% }\end{array}$} & $\begin{array}{c}\text { Капитальные } \\
\text { вложения } \\
\text { в производство, \% }\end{array}$ & $\begin{array}{c}\text { Эксплуатация } \\
\text { и обслуживание, } \\
\text { утилизация, \% }\end{array}$ \\
\hline Космические & 18 & 66 & 16 \\
\hline Самолеты с неподвижным крылом & 20 & 39 & 31 \\
\hline Самолеты с подвижным крылом & 15 & 52 & 39 \\
\hline Ракеты & 27 & 43 & 68 \\
\hline $\begin{array}{l}\text { Электроника (программное } \\
\text { обеспечение) }\end{array}$ & 22 & 31 & 54 \\
\hline Корабли & 1 & 37 & 70 \\
\hline Наземная техника & 9 & 30 & \\
\hline $\begin{array}{l}\text { Автоматизированные } \\
\text { информационные системы }\end{array}$ & & & \\
\hline
\end{tabular}

Эксплуатация РТС может быть штатной, опытной, подконтрольной, лидерной, технической [3]. Далее по тексту рассматривается штатная эксплуатация изделия военной техники, которая заключается в эксплуатации изделия военной техники в соответствии с требованиями эксплуатационной документации, а под определением «радиотехническое средство» будут подразумеваться радиолокационные комплексы (РЛК), радиолокационные станции (РЛС), радиовысотомеры.

Понятие «эксплуатация» определено как стадия жизненного цикла, включающая в себя следующие этапы: ввод в эксплуатацию, приведение в установленную степень готовности к использованию по назначению, поддержание в установленной степени готовности к использованию по назначению, использование по назначению, хранение, транспортирование, снятие с эксплуатации, списание [4]. Каждая стадия характеризуется определенным набором затрат.

Затраты $C_{\text {вводв экпл }}$ на ввод в эксплуатацию и подготовительные мероприятия, необходимые для приведения РТС в состояние использования по назначению, складываются из затрат на разработку документации, развертывание РТС на позиции. Рассмотрим более детально каждый из элементов затрат.

Затраты $C_{\text {док }}$ на разработку руководящих документов, регламентирующих боевое применение РТС, определяются в соответствии с формулой

$$
C_{\text {док }}=k_{\text {экз }} \cdot C_{\text {изд }}+u \cdot C_{\text {разраб }},
$$

где $k_{\text {экз }}$ - количество экземпляров документации; $C_{\text {изд }}-$ стоимость издания одного экземпляра; $C_{\text {разраб }}$ - стоимость разработки одного авторского листа; $u$ - количество авторских листов.

Затраты $C_{\text {пп }}$ на подготовку позиции

$$
C_{\text {пп }}=C_{\text {раб }} \cdot k_{\text {поз }} \text {, }
$$


где $C_{\text {раб }}$ - стоимость работ по подготовке позиции; $k_{\text {поз }}$ - коэффициент, учитывающий сложность работ при подготовке позиции в зависимости от физико-географического расположения подразделения.

Затраты $C_{\text {разверт }}$ на развертывание РТС с привлечением бригад промышленности можно представить как

$$
C_{\text {разверт }}=O \cdot \sum_{i=1}^{N_{\text {оп }}} T_{i} \cdot k_{\text {сложн } i},
$$

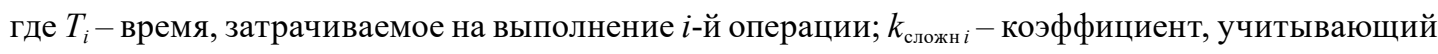
сложность проведения $i$-й операции (табл. 1); $O$ - стоимость нормо-часа выполнения $i$-й операции; $N_{\text {оп }}$ - общее количество операций.

Коэффициент, учитывающий сложность проведения операции, определяется в соответствии с данными из табл. 2

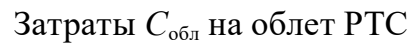

Суммарные затраты на ввод в эксплуатацию и приведение в установленную степень готовности к использованию по назначению РТС будут рассчитываться по следующей формуле:

$$
C_{\text {ввод в экспл }}=C_{\text {док }}+C_{\text {пा }}+C_{\text {разверт }}+C_{\text {обл }} \text {. }
$$

Затраты $C_{\text {бг }}$ на поддержание РТС в установленной степени готовности к использованию по назначению РТС включают в себя затраты на проведение технического обслуживания, затраты на плановый и неплановый ремонты.

Техническое обслуживание за первый год эксплуатации включает в себя контрольный осмотр (КО), ежедневное техническое обслуживание (ЕТО), техническое обслуживание №1 (ТО-1), техническое обслуживание №2 (ТО-2), сезонное техническое обслуживание (СО).

Затраты на проведение контрольного осмотра и ежедневного технического обслуживания можно исключить из дальнейшего рассмотрения, так как они не оказывают существенного влияния на общий уровень затрат.

Тогда совокупные затраты на ТО будут складываться из затрат на проведение TO-1 и TO-2, которое, как правило, совмещено с сезонным обслуживанием. Будем считать, что ежегодно

Таблица 2. Значения коэффициентов сложности работ

\begin{tabular}{|c|c|c|}
\hline № ח/П & $\begin{array}{c}\text { Наименование } \\
\text { операции }\end{array}$ & \\
\hline 1 & $\begin{array}{l}\text { Подъем, опускание и перемещение тяжеловесных предметов (грузов) без } \\
\text { применения подъемно-транспортного оборудования }\end{array}$ & 2 \\
\hline 2 & $\begin{array}{l}\text { Работы на высоте (свыше } 5 \text { м) при отсутствии строительных лесов, подмостей, без } \\
\text { применения телескопических подъемных устройств и т.п. }\end{array}$ & 1,8 \\
\hline 3 & $\begin{array}{l}\text { Погрузка, разгрузка и транспортирование баллонов со взрывоопасными и } \\
\text { ядовитыми веществами, а также сосудов, работающих под давлением }\end{array}$ & 1,4 \\
\hline 4 & Проведение работ с напряжение более 380 В & 1,6 \\
\hline 5 & Проведение работ с источниками СВЧ-излучения & 1,2 \\
\hline
\end{tabular}

Table 2. The values of the work complexity coefficients 
проводится десять технических обслуживаний №1 (ТО-1) и два технических обслуживания №2 (ТО-2), совмещённых с СО.

Тогда затраты на проведение ТО можно представить как

$$
C_{\mathrm{To}}=10 \cdot C_{\mathrm{Mc} 1}+2 \cdot C_{\mathrm{мc2}}+C_{\text {раб̆ то }},
$$

где $C_{\text {мс1 }}$ - стоимость материальных средств, затраченных для проведения технического обслуживания №1; $C_{\text {мс2 }}$ - стоимость материальных средств, затраченных для проведения технического обслуживания №2 и сезонного технического обслуживания; $C_{\text {раб то }}-$ стоимость работ бригады промышленности при проведении ТО.

В свою очередь, стоимость работ бригады промышленности при проведении ТО рассчитывается следующим образом:

$$
C_{\text {исп бр пс }}=B_{\text {др }} \cdot K_{\text {др }}\left(C_{\text {топ }} \cdot R_{\text {топ }}+C_{\text {гсм }} \cdot R_{\text {гсм }}\right),
$$

где $T_{i}$ - время, затрачиваемое на выполнение $i$-й операции; $O$ - стоимость нормо-часа выполнения $i$-й операции; $N_{\text {то }}$ - общее количество операций технического обслуживания.

Затраты на расход одиночного и группового комплектов ЗИП:

$$
C_{\text {эзип }}=\frac{p}{T_{\text {о }}} \cdot\left(1-K_{\mathrm{p}}\right) \cdot \overline{C_{\text {эл }}}+\frac{p}{R} \cdot C_{\text {зип }}
$$

где $p$ - годовая норма расхода ресурса РТС; $T_{\mathrm{o}}$ - средняя наработка РТС на отказ; $K_{\mathrm{p}}$ - коэффициент ремонтопригодности элементов, учитывающий долю элементов замены РТС, подлежащих ремонту в войсковых ремонтных органах и на предприятиях промышленности; $\overline{C_{\text {эл }}}-$ средняя стоимость элемента замены РТС; $R$ - ресурс РТС; $C_{\text {зип }}$ - стоимость ЗИП, используемого для обеспечения ремонтопригодности РТС.

Совокупные затраты на приобретение ЗИП $C_{\text {зип }}$ можно определить по формуле

$$
C_{\text {зип }}=\left(C_{\text {зип-о }}+\frac{1}{N} \cdot C_{\text {зип-г }}\right),
$$

где $C_{\text {зип-о }}, C_{\text {зип-г }}$ - стоимость одиночного и группового комплектов ЗИП соответственно; $N$ - количество образцов однотипных РТС, обслуживаемых одним комплектом ЗИП-Г.

На практике используется классификация ремонтов:

- по степени восстановления ресурса: текущий ремонт, при котором ресурс не восстанавливается; средний ремонт, при котором осуществляется частичное восстановление ресурса; капитальный (капитальный с модернизацией) ремонт, при котором осуществляется восстановление полного, или близкого к полному ресурса;

- по времени проведения: плановый ремонт; неплановый ремонт;

- по совмещению времени и места проведения ремонта составных частей образца ВВТ: комплексный ремонт; специализированный ремонт.

Затраты $C_{\text {рем план }}$ на проведение плановых видов ремонтов РТС можно определить на основе формулы

$$
C_{\text {рем план }}=\sum_{i=1}^{M} m_{i} \cdot C_{\mathrm{peм} i},
$$


где $M$ - виды ремонта, которые могут проводиться на образце в течение года; $m_{i}-$ количество -х видов ремонта образца в год; $C_{\text {рем } i}-$ стоимость $i$-го вида ремонта образца.

Затраты $C_{\text {рем неплан }}$ на проведение неплановых видов ремонтов РТС можно определить как

$$
C_{\text {рем план }}=\widehat{C}_{\text {рем неплан }} \cdot N_{\text {отк }},
$$

где $\widehat{C}_{\text {рем неплан }}-$ средние затраты на приведение образца в работоспособное состояние; $N_{\text {отк }}-$ среднее количество отказов РТС за год.

$$
N_{\text {отк }}=\frac{T_{\text {нар }}}{T_{\text {отк }}},
$$

где $T_{\text {отк }}-$ средняя наработка на отказ РТС; $T_{\text {нар }}$ средняя наработка РТС за год.

Для РТС дежурного режима средняя наработка РТС за год $T_{\text {нар }}$ будет рассчитываться следующим образом:

$$
T_{\text {нар }}=B_{\text {др }} \cdot K_{\text {др }},
$$

где $B_{\text {др }}$ - базовая наработка РТС дежурного режима, соответствующая годовым нормам расхода ресурса радиоэлектронной техники РТВ ПВО на мирное время; $K_{\text {др }}$ - коэффициент использования РТС дежурного режима в зависимости от типа подразделения.

В свою очередь, для РТС боевого режима средняя наработка за год ( $\left.T_{\text {нар }}\right)$ будет рассчитываться так:

$$
T_{\text {нар }}=B_{\text {бр }} \cdot K_{\text {бр }},
$$

где $B_{\text {бр }}$ - базовая наработка РТС боевого режима, соответствующая годовым нормам расхода ресурса радиоэлектронной техники РТВ ПВО на мирное время; $K_{\text {бр }}$ коэффициент использования образца РЭТ боевого режима в зависимости от типа подразделения.

Тогда суммарные затраты на поддержание в установленной степени готовности к использованию по назначению РТС могут быть определены с помощью следующей формулы:

$$
C_{\text {бг }}=C_{\text {то }}+C_{\text {э зип }}+C_{\text {рем план }}+C_{\text {рем неплан }} .
$$

Образцы РТС в зависимости от использования по назначению подразделяются на РЛС (РЛК) боевого и дежурного режимов, а их использование может быть как от промышленной сети, так и от штатных агрегатов питания. Следовательно, расчет затрат на использование РТС по назначению $C_{\text {исп назн }}$ необходимо производить раздельно для каждого случая.

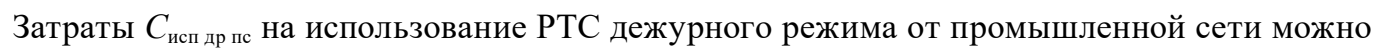
определить как

$$
C_{\text {исп др пс }}=B_{\text {др }} \cdot K_{\text {др }} \cdot P_{\text {рлс }} \cdot C_{\text {кв } / ч} \cdot K_{\text {сез }},
$$

где $B_{\text {др }}$ - базовая наработка РТС дежурного режима; $K_{\text {др }}-$ коэффициент использования РТС дежурного режима в зависимости от типа подразделения (табл. 3); $C_{\text {квт/ч }}-$ стоимость одного кВт/ч электроэнергии; $K_{\text {сез }}-$ сезонный коэффициент.

Коэффициент использования РТС дежурного режима в зависимости от типа подразделения определяется в соответствии с данными табл. 3. 
Таблица 3. Значения коэффициентов использования РТС в зависимости от типа подразделения

Table 3. Values of radio engineering means usage factors depending on the type of subdivision

\begin{tabular}{|c|c|c|c|}
\hline $\begin{array}{l}\text { № } \\
\Pi / \Pi\end{array}$ & Тип подразделения & $\begin{array}{c}\text { Коэффициент } \\
\text { использования РТС } \\
\text { дежурного режима }\end{array}$ & $\begin{array}{c}\text { Коэффициент } \\
\text { использования РТС } \\
\text { боевого режима }\end{array}$ \\
\hline 1 & $\begin{array}{l}\text { Подразделения, несущие боевое дежурство с } \\
\text { включенной РЭТ круглосуточно и обеспечивающие } \\
\text { полеты авиации }\end{array}$ & 9,5 & 3,1 \\
\hline 2 & $\begin{array}{l}\text { Подразделения, несущие боевое дежурство с } \\
\text { включенной РЭТ по графику и обеспечивающие } \\
\text { полеты авиации }\end{array}$ & 6 & 2,5 \\
\hline 3 & $\begin{array}{l}\text { Подразделения, несущие боевое дежурство с } \\
\text { включенной РЭТ по команде и обеспечивающие } \\
\text { полеты авиации }\end{array}$ & 4 & 2,5 \\
\hline 4 & $\begin{array}{l}\text { Подразделения, несущие боевое дежурство с } \\
\text { включенной РЭТ круглосуточно, в том числе с ПН } \\
\text { авиации }\end{array}$ & 8,5 & 1,8 \\
\hline 5 & $\begin{array}{l}\text { Подразделения, несущие боевое дежурство с } \\
\text { включенной РЭТ по графику, в том числе с ПН } \\
\text { авиации }\end{array}$ & 3,5 & 1,8 \\
\hline 6 & $\begin{array}{l}\text { Подразделения, несущие боевое дежурство с } \\
\text { включенной РЭТ по команде, в том числе с ПН } \\
\text { авиации }\end{array}$ & 1,2 & 1,25 \\
\hline 7 & $\begin{array}{l}\text { Подразделения, несущие боевое дежурство с } \\
\text { включенной РЭТ по команде }\end{array}$ & 1 & 1 \\
\hline
\end{tabular}

Сезонный коэффициент учитывает увеличение потребления электроэнергии РТС при использовании по назначению (обогрев антенной системы, поддержание температурного режима, необходимого для нормального функционирования аппаратуры и работы боевого расчета). Данный коэффициент зависит от климатических условий региона и значений потребляемой образцом мощности в летний и зимний период.

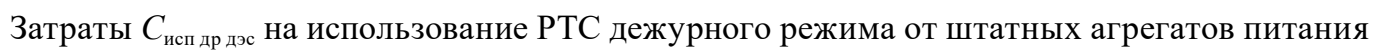
можно определить на основе формулы вида

$$
C_{\text {исп др дэс }}=B_{\text {др }} \cdot K_{\text {др }}\left(C_{\text {топ }} \cdot R_{\text {топ }}+C_{\text {гсм }} \cdot R_{\text {гсм }}\right),
$$

где $B_{\text {др }}$ - базовая наработка РТС дежурного режима; $K_{\text {др }}$ - коэффициент использования РТС дежурного режима в зависимости от типа подразделения; $C_{\text {топ }}$ стоимость израсходованного топлива; $R_{\text {топ }}$ - количество израсходованного топлива; $C_{\text {гем }}-$ стоимость остальных израсходованных горючесмазочных материалов; $R_{\text {гем }}$ - количество израсходованных горючесмазочных материалов.

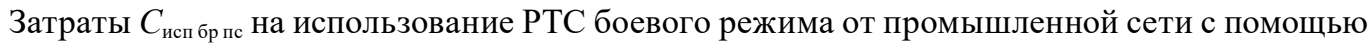
выражения

$$
\begin{aligned}
C_{\text {исп бр пс }}=B_{\text {бр }} \cdot K_{\text {бр }} \cdot P_{\text {рлс }} \cdot C_{\text {квт } / \text { ч }} \cdot K_{\text {сез }}, \\
-353-
\end{aligned}
$$


где $B_{\text {бр }}$ - базовая наработка РТС боевого режима; $K_{\text {бр }}-$ коэффициент использования РТС боевого режима в зависимости от типа подразделения; $C_{\mathrm{kв} / 4}-$ стоимость одного кВт/ч электроэнергии; $K_{\text {сез }}$ - сезонный коэффициент.

Затраты на использование РТС боевого режима от штатных агрегатов питания можно определить как

$$
C_{\text {энерг }}=B_{\text {бр }} \cdot K_{\text {бр }} \cdot P \cdot C_{\text {квт/ч }} \cdot K_{\text {сез }},
$$

где $B_{\text {бр }}$ - базовая наработка РТС боевого режима; $K_{\text {бр }}$ - коэффициент использования РТС боевого режима в зависимости от типа подразделения; $C_{\text {топ }}-$ стоимость израсходованного топлива; $R_{\text {топ }}-$ количество израсходованного топлива; $C_{\text {гем}}-$ стоимость остальных израсходованных горючесмазочных материалов; $R_{\text {гем}}$ - количество израсходованных горючесмазочных материалов.

Затраты $C_{\text {лс }}$ на содержание личного состава боевого расчета определяются на основе формулы

$$
C_{\text {лс }}=C_{\text {оф }} \cdot N_{1}+C_{\text {серж }} \cdot N_{2}+C_{\text {солд }} \cdot N_{3},
$$

где $C_{\text {оф }}, C_{\text {серж}}, C_{\text {солд }}$ - годовые затраты на содержание одного офицера, одного сержанта и одного солдата соответственно; $N_{1}, N_{2}, N_{3}$ - количество офицеров, сержантов, солдат, входящих в расчет РТC.

Тогда суммарные затраты на использование по назначению РТС будут рассчитаны по формуле

$$
C_{\text {исп назн }}=C_{\text {энерг }}+C_{\text {лс }},
$$

где $C_{\text {энерг }}$ - затраты на электроэнергию, потребляемую в зависимости от его типа и вида работы.

Затраты на электроэнергию при использовании РТС дежурного режима от промышленной сети можно определить как

$$
C_{\text {энерг }}=B_{\text {др }} \cdot K_{\text {др }} \cdot P \cdot C_{\text {квт/ч }} \cdot K_{\text {сез }},
$$

где $B_{\text {др }}$ - базовая наработка РТС дежурного режима; РЛС; $K_{\text {др }}$ - коэффициент использования РТС дежурного режима в зависимости от типа подразделения; $P$ - потребляемая мощность PTC; $C_{\text {квт/ч }}-$ стоимость одного кВт/ч электроэнергии; $K_{\text {сез }}-$ сезонный коэффициент.

Затраты на электроэнергию при использовании РТС дежурного режима от штатных агрегатов питания можно определить как

$$
C_{\text {энерг }}=B_{\text {др }} \cdot K_{\text {др }} \cdot\left(C_{\text {топ }} \cdot R_{\text {топ }}+C_{\text {гсм }} \cdot R_{\text {гсм }}\right),
$$

где $B_{\text {др }}$ - базовая наработка РТС дежурного режима; РЛС; $K_{\text {др }}$ - коэффициент использования РТС дежурного режима в зависимости от типа подразделения; $C_{\text {топ }}-$ стоимость израсходованного топлива; $R_{\text {топ }}-$ количество израсходованного топлива; $C_{\text {гем }}-$ стоимость остальных израсходованных горючесмазочных материалов; $R_{\text {гем}}-$ количество израсходованных горючесмазочных материалов.

Затраты на электроэнергию при использовании РТС боевого режима от промышленной сети можно определить на основе формулы

$$
-354-
$$




$$
C_{\text {энерг }}=B_{\text {бр }} \cdot K_{\text {бр }} \cdot P \cdot C_{\text {квт } / ч} \cdot K_{\text {сез }},
$$

где $B_{\text {бр }}$ - базовая наработка РТС боевого режима; РЛС; $K_{\text {бр }}$ - коэффициент использования РТС боевого режима в зависимости от типа подразделения; $P$ - потребляемая мощность РТС; $C_{\mathrm{kв} / 4}-$ стоимость одного кВт/ч электроэнергии; $K_{\text {сез }}-$ сезонный коэффициент.

Затраты на электроэнергию при использовании РТС боевого режима от штатных агрегатов питания определяются как

$$
C_{\text {энерг }}=B_{\text {бр }} \cdot K_{\text {бр }} \cdot\left(C_{\text {топ }} \cdot R_{\text {топ }}+C_{\text {гсм }} \cdot R_{\text {гсм }}\right),
$$

где $B_{\text {бр }}$ - базовая наработка РТС боевого режима; $K_{\text {бр }}$ - коэффициент использования РТС боевого режима в зависимости от типа подразделения; $C_{\text {топ }}$ - стоимость израсходованного топлива; $R_{\text {топ }}$ - количество израсходованного топлива; $C_{\text {гем }}-$ стоимость остальных израсходованных горючесмазочных материалов; $R_{\text {гем }}$ - количество израсходованных горючесмазочных материалов.

Затраты $C_{\text {хран }}$ на хранение РТС рассчитываются как

$$
C_{\text {хран }}=C_{\text {консервац }}+C_{\text {площ }}+C_{\text {то хран }}+C_{\text {расконсервац }},
$$

где $C_{\text {консервац }}$ - затраты на проведение консервации РТС перед закладкой на хранение; $C_{\text {площ }}-$ затраты на содержание площадей для хранения; $C_{\text {то хран }}-$ затраты на проведение технического обслуживания при хранении, которые включают в себя; $C_{\text {расконсрвац }}-$ затраты на расконсервацию РТС после хранения.

Затраты $C_{\text {трансп }}$ на транспортирование РТС будут зависеть от типа используемого транспорта: железнодорожный, морской, речной, воздушный, автомобильный и т.д.

Затраты $C_{\text {снят }}$ на снятие РТС с эксплуатации будут включать в себя затраты на проведение мероприятий по прекращению эксплуатации.

Затраты $C_{\text {спис }}$ на списание РТС для передачи на ликвидацию (утилизацию) можно определить как

$$
C_{\text {спис }}=C_{\text {утил гк }}-C_{\text {возвр }},
$$

где $C_{\text {утил гк }}$ - затраты на утилизацию РТС в соответствии с государственным контрактом; $C_{\text {возвр }}-$ стоимость реализованных материалов, полученных при утилизации (лом черного и драгоценных металлов, автомобильные базовые шасси и т.д.).

Годовые совокупные затраты на эксплуатацию РТС определим с помощью формулы

$$
C_{\text {общ }}=C_{\text {ввод в экспл }}+C_{\text {бг }}+C_{\text {исп назн }}+C_{\text {трансп }}+C_{\text {снят }}+C_{\text {спис }} \cdot
$$

Прогнозирование стоимости жизненного цикла это необходимый инструмент при принятии управленческого решения, проектировании технического задания, планировании выполнения отдельных этапов.

Причем расходы, осуществляемые на разных этапах жизненного цикла образца вооружения, не могут автоматически суммироваться без соответствующего учета стоимости денег во времени. Следовательно, они должны быть приведены к их текущей стоимости на момент принятия решения о разработке образца. Лишь после этого расходы, преобразованные в со- 
ответствующую им текущую оценку, могут быть использованы для калькуляции стоимости жизненного цикла в целом или отдельной его стадии. Этот эквивалент будущих расходов в оценке на базовую дату называется приведенной (дисконтированной) стоимостью расходов. Ставка дисконтирования представляет собой процентную ставку, на основе которой осуществляется процесс приведения (дисконтирование) будущих расходов в их оценке, приведенной на текущую дату, отражающей стоимость денег во времени [5].

Эквивалент будущей стоимости на текущий момент можно рассматривать как денежные средства, которые необходимо вложить сегодня по процентной ставке, равной ставке дисконтирования, чтобы удовлетворить потребность в денежных средствах в будущем или на момент, установленный проектной документацией.

Следующие два уравнения используются для преобразования будущих затрат в настоящую стоимость и наоборот:

$$
\begin{aligned}
& F=P(1+r)^{n}, \\
& P=F\left[1 /(1+r)^{n}\right],
\end{aligned}
$$

где $P$ - текущая стоимость; $F$ - будущая стоимость; $r$ - ставка дисконтирования; $n$ - количество интервалов прогнозирования.

В целом анализ затрат жизненного цикла РТС не отличается от других методов анализа. Однако поскольку финансирование осуществляется за счет бюджетных средств, необходимо учитывать специфику, присущую публичным проектам. Прежде всего, для оценки социальнозначимых проектов применяется метод анализа, получивший название «затраты-выгоды» («cost-benefit analyses»).

Анализ проводится в два этапа. На первом выполняется оценка затрат $\left(C_{t}\right)$ и выгод $\left(B_{t}\right)$, возникающих в течение каждого года $(t)$ в ходе реализации программы. На втором этапе производится вычисление чистой приведенной стоимости ( $N P V)$ программы путем суммирования дисконтированных будущих затрат и выгод. Именно на втором этапе необходимо правильно определить ставку дисконтирования для вычисления чистой приведенной стоимости [6]:

$$
N P V=\sum_{t=1}^{n} \frac{B_{t}}{(1+r)^{t}}-\sum_{t=1}^{n} \frac{C_{t}}{(1+r)^{t}} .
$$

В связи с неблагоприятным инвестиционным климатом уровень рисков значительно выше, поэтому расчет ставки дисконта следует проводить с учетом более высокой премии за риски:

$$
r=r_{0}+\sum_{i}^{n} r_{i},
$$

где $r_{0}$ - безрисковая ставка дисконтирования; $r_{i}-$ премия за риск.

Безрисковая ставка отражает доход по вложениям, осуществляемым при отсутствии риска. При этом необходимо выполнение двух условий: во-первых, отсутствует риск неплатежа, во-вторых, для обеспечения ожидаемой отдачи от некоторого финансового актива с определенностью необходимо исключить риск реинвестирования. Поэтому в мировой практике в 
качестве безрисковой ставки используется ставка дохода по долгосрочным государственным ценным бумагам.

Премия за риск должна учитывать проектные риски, с которыми может столкнуться заказчик в лице Министерства обороны РФ, среди которых выделим:

1) риск ликвидации предприятия-исполнителя;

2) риск завышения (занижения) цены контракта предприятием-исполнителем;

3) риск срыва сроков выполнения работ предприятием-исполнителем;

4) риск масштаба проекта.

Таким образом, в статье предложена методика оценки затрат на эксплуатацию радиотехнического средства с учетом коэффициента дисконтирования. По сравнению с другими стадиями жизненного цикла образца радиотехнического средства затраты на его эксплуатацию будут намного больше и зависят от продолжительности стадии эксплуатации РТС.

\section{Список литературы}

[1] Допира Р.В., Смолкин М.А., Бердышев В.П., Копылов В.А. Показатель техникоэкономического анализа и выбора вариантов построения наземных радиолокационных станций. Программные продукты и системы, 2013, 2, 63-69 [An indicator of engineering-economic analysis and the choice of ground-based radar alternate design. Soft \& System, 2013, 2, 63-69 (in Russian)]

[2] Демидов Б.А. Теория и методы военно-научных исследований вооружения и военной техники. Харьков: ВИРТА, 1990. 141-148 [Demidov B.A. Theory and methods of military-scientific research of weapons and military equipment. Kharkov: VIRTA, 1990. 141-148 (in Russian)]

[3] ГОСТ РВ 15.004-2004. Военная техника. Стадии жизненного цикла изделий и материалов. Введ. 2004. 12-30. М.: ФАТР, 2004. 23. [GOST RW 15.004-2004 Military equipment. Stages of the life cycle of products and materials. Put in place 2004. 12-30 FATR, 2004. 23 (in Russian)]

[4] ГОСТ РВ 0101-001-2007. Эксплуатация и ремонт изделий военной техники. Термины и определения. Введ. 2008-01-01. М.: Изд-во стандартов, 2008. 19. [GOST RW 001-001-2007. Operation and repair of wares. Terms and Definitions. Put in place $2008-01-01$. Publishing standards 2008. 19 p. (in Russian)]

[5] Ильин М.О. К вопросу о дисконтировании денежных потоков [Электронный ресурс]. URL: https://srosovet.ru/content/files/00/19/d6.pdf (дата обращения 06.10.2017) [Ilin M.O. On the issue of discounting cash flows URL: https://srosovet.ru/content/files/00/19/d6.pdf. circulation date 10/06/2017 (in Russian)]

[6] Бухонова С.М., Кафтан Е.С., Климашевский К.А. Определение коэффициента дисконтирования в российских условиях, параметры ставки дисконтирования. Вестник БГТУ им. В.Г. Шухова. 2013. 4. 116-119 [Bukhonova S.M. Kaftan E.S. Klimashevsky K.A. Determination of the discounting factor in Russian conditions, the parameters of the discount rate. Bulletin of BGTU. V.G. Shukhova. 2013. 4. 116-119 (in Russian)] 